\title{
Agua y espacio urbano. Algunas consideraciones teóricas a propósito de la relación entre ciudad y río*
}

\author{
Albert Santasusagna Riu \\ Joan Tort Donada \\ Universitat de Barcelona \\ asantasusagna@ub.edu \\ jtort@ub.edu
}

\section{Resumen}

En este artículo se propone una aproximación al estudio de la relación entre el medio fluvial (el rio) y el espacio urbano (la ciudad) desde un punto de vista teórico y conceptual. Se parte de una reflexión que permite realizar una serie de matices terminológicos que se consideran imprescindibles para comprender la complejidad del sistema urbano-fluvial. Los conceptos objeto de análisis han sido, en su mayor parte, acuñados y difundidos desde la geografía moderna, pero también estudiados desde materias afines como el urbanismo y la arquitectura. Asimismo, se trata de conceptos que han tenido una traducción particular según la tradición y el contexto académicos. Nuestra aportación se centra en el análisis y la sistematización de este cuerpo terminológico, con la finalidad de establecer una base teórica que permita comprender mejor la relación entre río y ciudad.

Palabras clave: agua; ciudad; paisaje del agua; relación entre ciudad y río; fachada fluvial

* La realización de este artículo ha sido posible gracias al desarrollo del proyecto científico postdoctoral concertado entre la Universitat de Barcelona y la Sociedad General de Aguas de Barcelona (AGBAR). Se inscribe en el marco del proyecto CSO2015-6787-C6-4-P del Ministerio de Economía y Competitividad del Gobierno de España y contó, asimismo, con el apoyo del Institut de Recerca de l'Aigua (IdRA) y del Grup de Recerca Ambiental Mediterrània (GRAM, 2017SGR1344), de la Universitat de Barcelona. 
Resum. Aigua i espai urbà. Algunes consideracions teòriques a propòsit de la relació entre ciutat $i$ riu

En aquest article es proposa una aproximació a l'estudi de la relació entre el medi fluvial (el riu) i l'espai urbà (la ciutat) des d'un punt de vista teòric i conceptual. Es parteix d'una reflexió que permet establir una sèrie de matisos terminològics que es consideren imprescindibles per comprendre la complexitat del sistema urbanofluvial. La major part dels conceptes objecte d'anàlisi han estat forjats i difosos des de la geografia moderna, però també estudiats des de matèries afins com ara l'urbanisme i l'arquitectura. Així mateix, es tracta de nocions que han tingut una traducció particular segons la tradició i el context acadèmics. La nostra aportació se centra en l'anàlisi i la sistematització d'aquest cos terminològic, amb la finalitat d'establir una base teòrica que permeti comprendre més bé la relació entre riu i ciutat.

Paraules clau: aigua; ciutat; paisatge de l'aigua; relació entre ciutat i riu; façana fluvial

Résumé. Eau et espace urbain. Quelques considérations théoriques sur la relation entre ville et fleuve

Cet article propose une approche de l'étude de la relation entre l'environnement fluvial (le fleuve) et l'espace urbain (la ville) d'un point de vue théorique et conceptuel. Il est basé sur une réflexion qui permet une série de nuances terminologiques considérées comme essentielles pour comprendre la complexité du système urbain-fluvial. Les concepts analysés ont été pour la plupart inventés et diffusés à partir de la géographie moderne, mais ils ont aussi étudiés à partir de sujets connexes tels que l'urbanisme et l'architecture. De même, ce sont des concepts qui ont eu une traduction particulière selon la tradition et le contexte académiques. Notre contribution se concentre sur l'analyse et la systématisation de ce corps terminologique afin d'établir une base théorique permettant une meilleure compréhension de la relation entre ville et fleuve.

Mots-clés: eau; ville; paysage de l'eau; relation ville-fleuve; front d'eau

Abstract. Water and urban space: Some theoretical considerations on the relationship between city and river

This paper proposes an approach to the study of the relationship between the fluvial environment (the river) and the urban space (the city) from a theoretical and conceptual viewpoint. It is based on a reflection that allows a series of terminological nuances considered essential to understand the complexity of the urban-river system. The concepts under analysis have been, for the most part, coined and disseminated by modern geography, but also studied in related fields such as urbanism and architecture. Likewise, these are concepts that have had a particular translation depending on the academic context and tradition. Our contribution focuses on the analysis and systematization of this terminological corpus in order to establish a theoretical basis that allows for a better understanding of the relationship between river and city.

Keywords: water; city; waterscape; city-river relationship; riverfront 


\section{Sumario}

1. Introducción

2. El agua en el paisaje. Los paisajes de dominante hídrica

3. El enfoque histórico-urbanístico en el estudio de ríos y ciudades
4. Una transformación reciente: waterfronts, riverfronts y fachadas urbanas 5. Recapitulación final Referencias bibliográficas

\section{Introducción}

La relación existente entre agua y espacio urbano ha sido analizada por varios autores desde múltiples puntos de vista y con una producción creciente de términos específicos para referirse a su interacción en cuanto a aspectos históricos, geográficos y ambientales. El agua, en la ciudad, se percibe como un elemento a gestionar a partir del control y de la percepción social del riesgo (Calvo García-Tornel, 2001; Olcina, 2007; Saurí et al., 2010), pero también desde la óptica del diseño de sistemas sostenibles de depuración, regeneración y permeabilización que garanticen su correcto abastecimiento y calidad (Rodríguez et al., 2014). A partir de su asunción como bien común - uno de los principios fundamentales de la Directiva Marco del Agua (2000/60/CE) y la nueva cultura del agua_, también se procura su consumo racional a través del análisis metabólico urbano (Naredo, 2009; Beltrán y Velázquez, 2015) y se reflexiona sobre los pros y los contras de su gestión pública o privada (Espluga et al., 2011). A su vez, el agua en el contexto urbano también se concibe como un recurso estético y artístico (Novoa, 1999; Martín-Vide, 1999; Béthemont et al., 2007; Corbella, 2016), así como una herramienta educativa y pedagógica (Cuello, 2010; Cuello y Cuello, 2016).

La gestión del medio fluvial en un entorno urbano es una de las manifestaciones explícitas del vínculo histórico entre agua y ciudad. A lo largo del siglo XX, en muchas ciudades mediterráneas y europeas, se estableció una relación con sus espacios fluviales respectivos que cabría calificar de pendular (Pellicer y Ollero, 2004): la expansión urbana sin contención, los vertidos procedentes de actividades industriales, la explotación de los recursos del entorno fluvial como materia prima para la construcción y la agricultura o la planificación de infraestructuras lineales (viarias y ferroviarias) y de gran magnitud (puertos, aeropuertos) en las inmediaciones de los espacios fluviales, han sido el reflejo de una presión antrópica sin precedentes. No obstante, también se han tomado medidas para paliar este escenario de deterioro, y tales medidas han supuesto, en algunos casos, la restauración o la rehabilitación del medio fluvial y, de forma complementaria, el aprovechamiento social de estos espacios a través de su consideración como zonas verdes y parques urbanos.

En el análisis de este contexto de transformación de los espacios fluviales en áreas urbanas han surgido una serie de conceptos que, presentes en trabajos científicos centrados en la interpretación del paisaje y el estudio del planea- 
miento urbano o en proyectos de carácter arquitectónico, han sido utilizados para caracterizar y comprender este cambio histórico. Conceptos que, en su mayor parte, han sido acuñados y difundidos desde la geografía moderna (waterscape, paisaje del agua, relación e interfaz entre ciudad y rio, espacio urbanofluvial) o estudiados desde materias afines como el urbanismo y la arquitectura (waterfront, riverfront, fachadas y frentes fluviales). Tomando como referencia lo señalado, en este artículo nos proponemos abordar el estudio conceptual de la relación entre medio fluvial y espacio urbano a partir de la profundización en el sentido y la razón de ser de los conceptos señalados; todo ello desde una perspectiva eminentemente teórica o epistemológica.

Se hace necesaria, en el contexto descrito, una revisión bibliográfica de autores especializados que permita los matices terminológicos imprescindibles para la comprensión de la complejidad del problema en su consideración global. Estos términos han tenido una traducción particular según el contexto académico y científico de los autores - principalmente, de tradición anglosajona, francesa y española—, y han dado lugar a estudios sobre la evolución, la transformación y la restauración del medio fluvial en la ciudad provenientes de diferentes campos disciplinarios. Este hecho se refleja en la estructura del artículo, con una primera parte centrada en la relación entre agua y paisaje; una segunda que incide en el enfoque histórico-urbanístico de los vínculos entre ciudades y ríos, y, finalmente, un tercer apartado que reúne una serie de conceptos frecuentemente usados en trabajos y proyectos urbanos y arquitectónicos que tratan de explicar una transformación reciente de los cursos fluviales en la ciudad. Nuestra aportación, pues, quiere centrarse en el análisis y la sistematización del corpus terminológico de referencia con la finalidad esencial de contribuir a su clarificación y, de este modo, hacer posible un uso más preciso y riguroso de estos conceptos en el debate científico que concierne a la relación entre la ciudad y el río.

\section{El agua en el paisaje. Los paisajes de dominante hídrica}

El Convenio Europeo del Paisaje (CEP), elaborado por el Consejo de Europa y aprobado en el año 2000, define el paisaje, en su primer artículo, como "cualquier parte del territorio tal como la percibe la población, cuyo carácter sea el resultado de la acción y la interacción de factores naturales y/o humanos» (art.1.a); una definición que se instrumenta, a lo largo del cuerpo normativo, en toda una serie de directrices orientadas a la protección, la ordenación y, como concepto clave, a la gestión del paisaje. Desde su aprobación y ratificación por los Estados miembros de la Unión Europea, en España, los esfuerzos para implementar estas directrices se han concretado en una serie de normas de rango estatal y autonómico que reconocen los valores colectivos, sociales y ambientales del paisaje. Este reconocimiento se subraya a través de la incorporación de la dimensión cultural, «dirigida a todos los paisajes, a los sobresalientes y a los banales, a los cotidianos y a los visitados, a la calidad del entorno vital de las personas» (Mata Olmo et al., 2010: 120). Se trata de una visión que 
remite, fundamentalmente, a una interpretación ambivalente y dual, y en cierto modo difusa, del vector paisajístico. Un vector que es entendido de un modo integrado y que no hace distinción entre el componente natural y el artificial. En el contexto de los paisajes con una dominante hídrica —que implica que, en ellos, el agua sea el principal protagonista-, existen dos términos que merecen nuestro análisis y atención: waterscape - propio de la literatura anglosajona sobre paisaje- y paysage de l'eau / paisaje del agua — que concierne a la geografía francesa y española. Se trata, a rasgos generales, de nociones que pueden considerarse equivalentes a nivel lingüístico, pero que admiten matices en el plano teórico. Analizaremos seguidamente tales nociones, lo que nos permitirá detectar dos enfoques distintos de la relación entre agua y paisaje.

\subsection{El concepto de waterscape. Una visión política y ecológica de la transformación del paisaje}

En clave moderna, uno de los discursos que más ha influido en campos como la ecología política o la antropología es el hibridismo. Partiendo de la concepción de la naturaleza como una construcción social (Proctor, 1998; Descola, 2005), Bruno Latour (1991) sostiene que el mundo occidental es capaz de generar cuasi-objetos (hibridos) que difuminan los límites entre lo natural y lo artificial. Estos híbridos se encuentran presentes, por ejemplo, en muchas de las creaciones propias de la biotecnología, como los organismos genéticamente modificados (OGM), en elaboraciones o «productos» de la biorobótica o, situándonos en otro plano, en el seno de fenómenos globales como el agujero de la capa de ozono.

Los hibridos, especialmente numerosos en el campo ambiental (Martí-Escayol, 2005), cobran una relevancia especial en el concepto específico de waterscape. Swyngedouw (1996) desarrolla este concepto en la literatura académica anglosajona y lo define sobre la base de una serie de términos que procuran, en última instancia, un fundamento al concepto de híbrido que introduce Latour:

A liminal landscape $[\ldots]$ where the cyborg character of the transgression between society's nature and nature's society is perpetually emptied out, filled in again, and transformed. This circulation of water is embedded in and interiorizes a series of multiple power relations along ethnic, gender and class lines. These situated power relations, in turn, swirl out and operate at a variety of interrelated geographical scale levels, from the scale of the body upward to the political ecology of the city to the global scale of uneven development. (Swyngedouw, 1996: 76)

Swyngedouw introduce, en su definición de waterscape, la consideración de dos aspectos fundamentales: por una parte, la profunda transformación antrópica de la naturaleza con efectos ecológicos singulares (transgression) y, por otra, la variable política — entendida, concretamente, desde la perspectiva ecosocial- . Esta última variable es concebida por el autor como fundamental en todo el proceso de cambio a través del tiempo. 
Desde las coordenadas conceptuales que acabamos de expresar, Swyngedouw sienta las bases del enfoque particular de una buena parte de los estudios de tradición anglosajona relacionados con la transformación urbana de los waterscapes (Zug, 2014; Karpouzoglou y Vij, 2017). Según Swyngedouw, la transformación del paisaje se observa como resultado de las políticas del agua desarrolladas en cada ámbito administrativo de planificación. Se trata de un hecho que incide en aspectos como el patrimonio (Anton et al., 2013), el diseño urbano (Huning y Frank, 2011) o, a múltiples escalas, en el sistema de gestión del agua (Ahlers et al., 2014) y su distribución, a menudo objeto de severas críticas por su reparto desigual y su dependencia respecto a determinados poderes económicos y políticos.

Un ejemplo de este proceso para Swyngedouw es, precisamente, el caso de España (Swyngedouw, 1999, 2015). Según el autor, la planificación y la gestión del agua durante el franquismo modificó de forma transcendental buena parte del territorio con la realización de grandes obras hidráulicas. A raíz de este proceso, el autor se plantea en qué sentido esta política puede haber condicionado la relación entre naturaleza y sociedad. Y se pregunta también si tal política ha coadyuvado a la producción de un waterscape sui géneris. En esta misma línea, otros estudios ajustados a la visión que acabamos de presentar son los que se han llevado a cabo en ciudades como Ámsterdam (Kinder, 2015), Viena (Gierlinger et al., 2013), Medellín (López-Rivera, 2013) y Yakarta (Kooy, 2014), en regiones fluviales como la del río Jordán (Zeitoun et al., 2013) o en países como Chile (Budds, 2008) y Sudáfrica (Loftus, 2007).

Si el caso español es, para Swyngedouw, un ejemplo paradigmático de la evolución del waterscape, la región italiana del Véneto constituye una inspiración homónima para el geógrafo cultural Denis Cosgrove. Según Vallerani (2018), los estudios de Cosgrove sobre la transformación del waterscape del Véneto a finales del siglo XVI representan una aportación pionera en este campo. Cosgrove (1993) sintetiza la crisis de poder que sufre el Véneto durante el Renacimiento tardío y la transición compleja de un poder político centrado en un dominio marítimo a un repliegue continental (conocidos como los «dominios de tierra firme»: Domini di Terraferma). Y como, en todo este proceso de cambio, la obra arquitectónica del archiconocido Andrea Palladio (1508-1580) tiene un papel notable a la hora de interpretar la transformación física, urbana y social del territorio.

Así pues, en la concepción de los waterscapes, el agua en el paisaje se convierte en la expresión local y global de la política — nacional, regional o localllevada a cabo. Y, por lo tanto, mediante la política hidráulica se acaba institucionalizando, a través del tiempo, un determinado "patrón» o una determinada «producción» de paisaje.

\subsection{El concepto de paisaje del agua en la geografía moderna francesa y española}

Diferentes autores de la tradición académica francesa y española han contribuido a desarrollar el concepto de paysage de l'eau y paisaje del agua, respecti- 
vamente. Sin embargo, y con carácter preliminar, señalábamos que su enfoque teórico ha sido distinto al de los autores referidos en el epígrafe anterior. En otras palabras: si bien el desarrollo del concepto de waterscape se hace, esencialmente, en el plano político y en el ecológico, el desarrollo conceptual del paisaje del agua incide más bien en otros planos: el histórico, el social y el cultural. Aun así, ambos enfoques comparten un mismo objetivo: el análisis y la comprensión de los múltiples vínculos entre naturaleza y sociedad.

Béthemont y Piégay (1998), por su parte, presentan una relación de las obras modernas que más han influido en el estudio de este tipo de paisajes en la tradición francesa. Dentro de esta relación, destacamos en particular la obra colectiva Les paysages de l'eau aux portes de la ville: Mise en valeur écologique et intégration sociale (Bravard et al., 1995) y las aportaciones, desde una perspectiva geomorfológica, relativas al Ródano (Bravard, 1987) y al Loira (Reyt, 1998a). En una publicación reciente, Béthemont y Bravard (2016) se refieren a los paysages de l'eau como aquellos paisajes sujetos a tres variables principales: el espacio - condicionado por las múltiples y variadas actividades que han llevado a cabo, durante siglos, las personas que habitan en las márgenes de una masa de agua-; el tiempo — que confiere un sentido unívoco a la relación histórica entre el ser humano y el agua-, y, finalmente, la acción humana — que afecta al medio, de diferente manera, a lo largo del tiempo-.

Sin dejar de movernos en la misma línea, es importante añadir a los trabajos mencionados las consideraciones que formulan Reyt (1998b) y RivièreHonneger (2008) a propósito del carácter dialéctico del agua en el paisaje. Reyt (1998b) hace hincapié en los efectos que tiene en la sociedad humana tanto la «bondad» de su presencia como la «tragedia» de su ausencia:

C'est le valeur paysagère d'une eau qui n'est plus seulement utilitaire, mais encore esthétique; une eau domestiquée qui encadre, décore et rassure, introduisant l'idée de nature au sein même des espaces anthropisés. Cette valeur s'exprime en termes de qualité de vie et de profit économique lié à l'attractivité des lieux [...] l'eau répresente également un valeur rare, dont le sentiment ou le "présentiment» de rareté s'ancre tour à tour dans l'aréisme du lieu ou le traumatisme d'une sécheresse et, au plus profond de notre inconscient collectif, dans un rapport presque animal à l'élément qui conditionne la survie et l'expansion d'une espèce. (Reyt, 1998b: 293)

De igual forma, Rivière-Honneger (2008) se refiere al agua como un elemento, a la vez, «creador» $\mathrm{y}$ «destructor»:

Paysages de terrasses et aménagements des eaux souterraines peinent à trouver une dynamique. L'observation montre, en effet, une évolution rapide des territoires où l'eau joue un rôle déterminant pour le paysage. Comment s'opèrent ces mutations et comment vont-elles s'opérer dans les années à venir? L'eau et le paysage offrent d'évidence une dialectique qui oscille entre construction et destruction $[\ldots]$ l'eau se révèle tour à tour comme un élément créateur ou comme un élément destructeur. Le passage d'un état à un autre est particulièrement riche à observer et à analyser. (Rivière-Honegger, 2008: 8) 
Dentro del ámbito de la geografía española encontramos, a su vez, varios estudios que sintetizan y aportan interesantes descripciones y definiciones del concepto de paisaje del agua. La definición de Pellicer et al. (1994) sobre los paisajes fluviales - esto es: los paisajes del agua referidos a un «vector hidráulico» concreto, como puede ser un curso fluvial - es claramente ilustrativa: este tipo de paisaje no es solo aquel que de forma natural presenta el agua como elemento central y originario, sino que también tiene en cuenta, necesariamente, los vínculos físicos e históricos de los ríos con elementos de origen humano, como las presas, los puentes o las ciudades.

Años más tarde, Pellicer (2001) introduce el concepto de paisajes fluviales urbanos para referirse, concretamente, al estudio de los ríos que discurren por una ciudad. Se trata, a nuestro modo de ver, de una de las interpretaciones más notables (y dotada, asimismo, de un indudable sentido metafórico) de este tipo de paisajes, especialmente cuando el autor afirma que un río «se convierte en cultura cuando penetra en la ciudad" (Pellicer, 2001: 283). Se intuye, en la misma línea que Swyngedouw, que la "huella humana» — desde la perspectiva económica y urbana, e incluso desde la perspectiva política- es la clave para comprender la evolución de estos paisajes:

El término paisaje fluvial comprende, en nuestra acepción, todos aquellos aspectos que se encuentran íntimamente relacionados con los cauces, las riberas y las llanuras de inundación (modelado, suelos, niveles freáticos, vegetación, cultivos, canales, azudes, puentes, muros de defensa, poblaciones...), además de ciertos rasgos del modelado del valle directamente ligados a la acción de los cursos fluviales. (Pellicer et al., 1994: 12)

En el paisaje fluvial urbano se reconocen la ciudad y la naturaleza. El río se convierte en cultura cuando penetra en la ciudad. La ciudad se abre a la naturaleza a través del río. Esta fusión profunda, sujeto de crisis, conflictos e intereses, es una de las manifestaciones más ricas de la vitalidad económica y ecológica de la ciudad. Es fiel exponente de la calidad ambiental, de la eficacia de la gestión, de la cultura y el civismo de sus habitantes y de la intensidad de los procesos especulativos. (Pellicer, 2001: 283)

En la misma línea que Pellicer y Reyt, Zoido (2008) propone una definición sobre los paisajes del agua en sentido amplio, es decir, no solamente por la presencia, acción o percepción del agua, sino también por su ausencia. Por lo tanto, y según esta premisa, un curso torrencial, seco la mayor parte del año, también formaría parte de un paisaje de este tipo. Además, Zoido remarca la capacidad que tiene el agua en el paisaje de «captar la mirada humana»:

[...] los paisajes del agua pueden definirse como sigue: «aquellos de cuyo carácter forma parte el agua por su presencia, acción o percepción». El agua está presente, en casi todos los paisajes, no resulta fácil desvincularla de la mayoría de ellos, pero obviamente no todos los paisajes son "paisajes del agua». Además, el agua, cuando está presente tiene con gran frecuencia una alta capacidad de determinar la forma objetiva del terreno y de convertirse en hecho dominante 
en la captación de la mirada humana relativa a un lugar. Sin duda son paisajes del agua los del litoral, los que contienen un curso fluvial importante o los espacios palustres, por señalar algunos ejemplos evidentes en los que una lámina de agua caracteriza decisivamente el paisaje. Además, hay que considerar paisajes del agua aquellos en los que aunque no sea visible se diferencian por su acción: una rambla seca, un cañón cárstico en el que el agua desaparece engullida en una sima, un campo cultivable en regadío tienen también la condición señalada aunque no veamos la causa que los produce o los hace ser distintos. (Zoido, 2008: 32)

Por su parte, Ribas (2007) pone el acento en la dimensión cultural de los paisajes del agua. E incluye, como ejemplo fundamental de este tipo de paisajes, las fachadas fluviales urbanas:

Por "paisajes del agua» entendemos aquellos paisajes que son producto resultante y perceptible de la combinación dinámica de elementos físicos (entre los cuales el agua es el más relevante) y elementos antrópicos (es decir, la acción humana), combinación que convierte el conjunto en un entramado social y cultural en continua evolución. Así, los principales elementos que definen los paisajes del agua serían el mar, los ríos, los torrentes, las ramblas, los humedales, los estanques, lagos y lagunas, los deltas... pero siempre en relación con aquellos otros elementos que denotan la permanencia histórica de las relaciones entre la sociedad y el agua, como serían las presas, los puentes, las acequias, los canales industriales, los molinos, la huerta, las fachadas fluviales de las ciudades, los caminos, las colonias industriales, los límites, las propiedades, la literatura, la pintura, etc. Encontramos magníficos ejemplos en los países mediterráneos, donde las relaciones entre sociedad y agua han creado un conjunto de paisajes de elevado valor ecológico, económico, cultural y simbólico, cada vez más apreciados y utilizados como bien público. (Ribas, 2007: 1)

Finalmente, dentro de la misma línea, destacamos la aportación de Frolova (2007). Esta autora ofrece una definición múltiple fundamentada en la gran complejidad conceptual del término; complejidad que, según la autora, descansa sobre dos conceptos clave. Por una parte, la complejidad de la propia definición de paisaje; por otra, el papel que desempeña el agua en este contexto:

[...] podríamos definir el paisaje del agua de diferentes maneras: como el paisaje en cuya estructura y funcionamiento el agua tiene una gran importancia, o como el paisaje en el que el agua es un factor limitante tanto en un sentido ecológico, como para su gestión, o como paisaje en cuyo origen y dinámica el agua es uno de sus elementos principales, etc. Todas estas definiciones atestiguan la doble complejidad del paisaje del agua como objeto de estudio. Habría que tener en cuenta, por un lado, las múltiples facetas de la noción de paisaje y, por otro, la del papel del agua en el paisaje, apoyándose el estudio de los paisajes del agua sobre estos dos conceptos fundamentales. (Frolova, 2007: 24)

Todas estas aproximaciones denotan, pues, que es necesario considerar los paisajes del agua como unas realidades híbridas; es decir, unas realidades donde 
Figura 1. Un ejemplo de paisaje del agua en un entorno urbano: el bosque de La Mitjana, en Lleida. Se trata de un área de bosque de ribera del río Segre de aproximadamente 90 hectáreas situada al noroeste del municipio. Su origen y formación se debe, de hecho, al efecto de retención de sedimentos fluviales producido por la presa del canal de Seròs desde principios del siglo $x x$

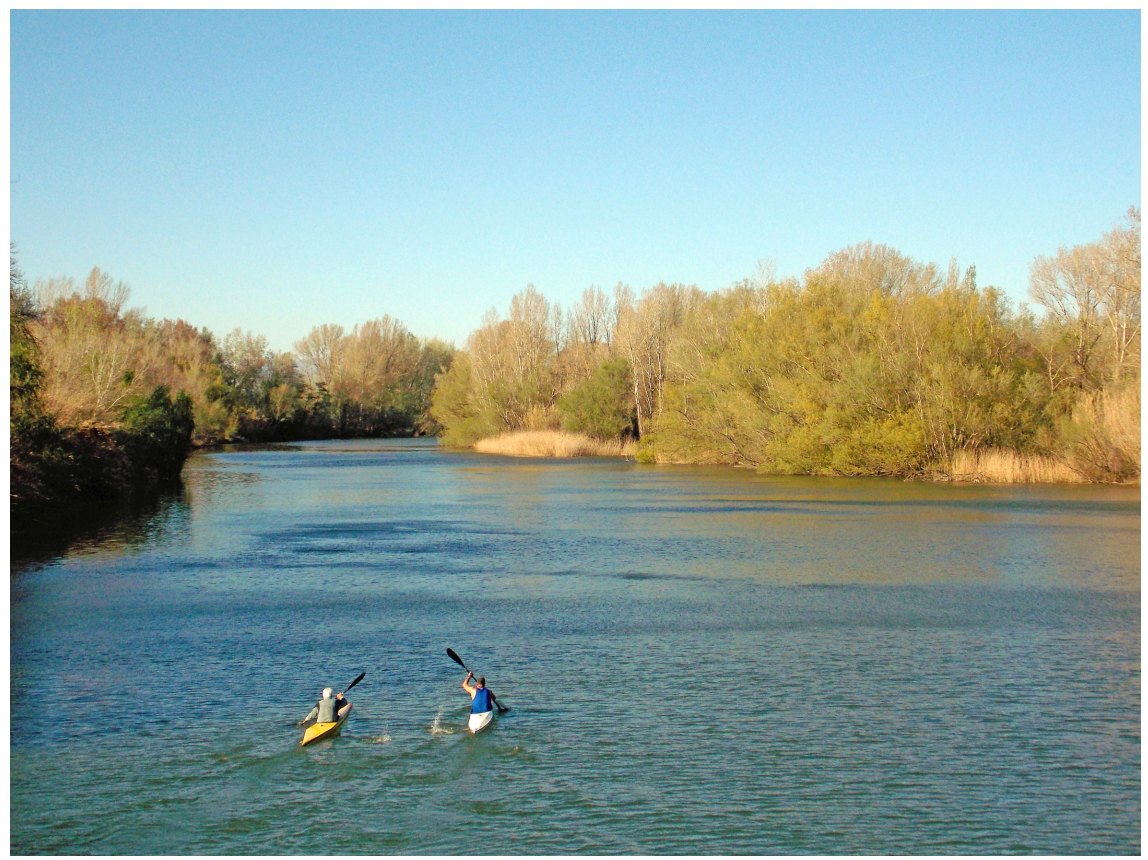

Fuente: archivo propio de Albert Santasusagna (tomada en marzo de 2015).

los elementos sociales y humanos propios del espacio urbano y los elementos naturales relativos al sistema fluvial se encuentran completamente entrelazados, formando una sola unidad, diversa y heterogénea (figura 1). Tal definición cumple con la razón de ser de los llamados paisajes culturales y patrimoniales (Mata Olmo y Fernández Muñoz, 2010) y trasciende, sobre la base de su concepción integrada, los enfoques que apuntan a una gestión y planificación sectorializada de los espacios fluviales. Considerando este argumento, por tanto, la ordenación de los paisajes del agua no ha de ser solamente un objetivo de la política hidráulica, sino también la base de su gestión a nivel paisajístico, patrimonial y cultural.

No queremos dar fin a este epígrafe sin recordar unas palabras que, a nuestro modo de ver, sintetizan todas las visiones destacadas hasta ahora. Se trata de un apunte de Martínez de Pisón (2009) en el que considera a los ríos no solamente como paisajes en sí mismos, sino también como creadores de cultura y patrimonio. El agua, pues, entendida como el origen fértil del ecosistema,y, a la vez, como un ecosistema consistente no solo en un "conjun- 
to de flora y fauna de ribera», sino también integrado por la especie humana entendida en un sentido amplio: los individuos y los pueblos en su dinámica y en su historia:

Los ríos, por último, no son solo ríos. Son paisajes. El río va entre sotos, se acompaña de arboledas, de huertas, de jardines, también de cicatrices de graveras y azudes, de presas, o del profundo sentido del agua en las civilizaciones, de referencias poéticas, de bautismos y símiles con la vida y la muerte, de pueblos, de vados y puentes. Los ríos son sus aguas y sus riberas, sus arboledas, sus distintos tramos y bandas. Los ríos son también sus saucedas y alisedas, los tarayales y choperas, las olmedas y fresnedas y su fauna asociada. Son sus pueblos y su historia, son su dinámica y su evolución. Los ríos de mi país no son canales, sino ríos. (Martínez de Pisón, 2009: 258)

\subsection{Los valores biofilicos de los paisajes del agua}

En el año 1993 se publicó The biophilia hypothesis, obra editada por Stephen R. Kellert y Edward O. Wilson. El objetivo de este estudio fue profundizar en el concepto de biofilia, formado por las palabras bio ('vida') y philia ('amistad'), término científico que Wilson ya había presentado previamente años antes en Biophilia: The human bond with other species (1984) y que define como "the innate tendency to focus on life and lifelike processes» (Wilson, 1984: 1). Kellert y Wilson sugieren que la mente humana está especialmente programada para establecer relaciones con el resto de seres vivos, y que estas relaciones revierten positivamente en el conocimiento, el bienestar y la propia salud del ser humano. En este sentido, ambos autores proponen una serie de valores que ponen de manifiesto la relación que se establece entre naturaleza y ser humano - valores que conceptúan, en su trabajo, como valores biofílicos-. En la práctica, la relación entre naturaleza y ser humano a la que se refieren Kellert y Wilson en The biophilia hypothesis tiene también, como veremos, una particular traducción a escala de los paisajes del agua.

Autores de distintas tradiciones académicas, como Ardillier-Carras (1998), Muñoz et al. (2006) y Ribas (2007), han tratado de sintetizar los valores propios de los paisajes del agua. Si bien los dos primeros autores proponen una distinción general entre tres y cuatro categorías de marcado carácter generalista -Ardillier-Carras (1998) constata el valor defensivo, patrimonial, estético y económico de los paisajes del agua, y Muñoz et al. (2006) se refieren a su valor especial, estético, social y ambiental-, Ribas (2007) señala nueve valores que se encuentran en perfecta consonancia con los valores biofilicos de Kellert (1993) y que comparamos y sintetizamos en la tabla 1.

Hablamos, pues, del valor productivo — relacionado con la multiplicidad de recursos que puede obtener el ser humano de los paisajes del agua, y que conecta con la dimensión utilitaria que propone Kellert-; del valor ecológico - que Kellert matiza adoptando la conjunción ecológico-científico, para subrayar el interés que suscita, desde un punto de vista científico, entre los huma- 
Tabla 1. Relación de los valores atribuidos a la naturaleza y a los paisajes del agua según varios autores

\begin{tabular}{|c|c|c|c|}
\hline $\begin{array}{l}\text { Valores biofílicos } \\
\text { (Kellert, 1993) }\end{array}$ & Definición & $\begin{array}{l}\text { Valores atribuidos } \\
\text { a los paisajes del } \\
\text { agua (Ribas, 2007) }\end{array}$ & Definición \\
\hline Utilitarian & $\begin{array}{l}\text { Interés en conservar los recursos por } \\
\text { sus beneficios básicos para la supervi- } \\
\text { vencia, la protección y la seguridad. }\end{array}$ & Productivo & $\begin{array}{l}\text { «La productividad de los paisa- } \\
\text { jes fluviales se puede medir a } \\
\text { través de actividades agrícolas } \\
\text { y ganaderas, forestales, cine- } \\
\text { géticas, turísticas, industriales, } \\
\text { etc.» }\end{array}$ \\
\hline Ecologistic-scientific & $\begin{array}{l}\text { Curiosidad que despierta la naturaleza } \\
\text { en el ser humano (el porqué de su fun- } \\
\text { cionamiento y la red de relaciones entre } \\
\text { los seres vivos). }\end{array}$ & Ecológico & $\begin{array}{l}\text { «Los paisajes del agua son } \\
\text { espacios con especial interés } \\
\text { natural e importantes conecto- } \\
\text { res ecológicos entre espacios } \\
\text { naturales (fluviales y terres- } \\
\text { tres).» }\end{array}$ \\
\hline Aesthetic & $\begin{array}{l}\text { Impacto emocional (belleza, apariencia } \\
\text { física) que produce la naturaleza en el } \\
\text { ser humano. }\end{array}$ & Estético & $\begin{array}{l}\text { «[...] continuidades arbóreas } \\
\text { que constituyen los bosques de } \\
\text { ribera, las fachadas urbanas flu- } \\
\text { viales, los conjuntos de elemen- } \\
\text { tos patrimoniales vinculados al } \\
\text { agua (los puentes, caminos y } \\
\text { pueblos), los fondos escénicos } \\
{[\ldots] . »}\end{array}$ \\
\hline Symbolic & $\begin{array}{l}\text { Carga comunicativa que proyecta la } \\
\text { naturaleza en la sociedad humana. }\end{array}$ & $\begin{array}{l}\text { Simbólico } \\
\text { e identitario }\end{array}$ & $\begin{array}{l}\text { «[...] gran carga simbólica } 0 \\
\text { identitaria para las poblaciones } \\
\text { locales [...] para establecer en } \\
\text { ella relaciones de pertenencia } 0 \\
\text { expresiones de nacionalidad.» }\end{array}$ \\
\hline Moralistic & $\begin{array}{l}\text { Sentimiento ético que despierta la } \\
\text { naturaleza en la especie humana para } \\
\text { conservar su harmonía. Tiene relación } \\
\text { con la espiritualidad. }\end{array}$ & Mitológico & $\begin{array}{l}\text { «[..] atribuciones simbólicas } \\
\text { colectivas relacionadas con } \\
\text { historias fantásticas o leyendas } \\
{[\ldots] . »}\end{array}$ \\
\hline Naturalistic & $\begin{array}{l}\text { Satisfacción humana — fascinación, } \\
\text { sorpresa y admiración- derivada del } \\
\text { contacto directo con la naturaleza. } \\
\text { El interés propio del carácter social de } \\
\text { la especie humana en «humanizar» } \\
\text { la naturaleza como resultado de su } \\
\text { «afecto». }\end{array}$ & Social & $\begin{array}{l}\text { «[...] la utilización que hacen } \\
\text { las personas de un paisaje del } \\
\text { agua para itinerarios, placer, } \\
\text { ocio, paseo, reposo, observación } \\
\text { de panorámicas (miradores, } \\
\text { recorridos turísticos), lugares de } \\
\text { encuentro, educación ambiental, } \\
\text { práctica del deporte, etc.» }\end{array}$ \\
\hline Dominionistic & $\begin{array}{l}\text { El deseo de los humanos de controlar } \\
\text { y domesticar la naturaleza desde el } \\
\text { mismo nacimiento como especie. }\end{array}$ & Histórico & $\begin{array}{l}\text { «...] tipologías constructivas } \\
\text { (molinos, puentes, presas), } \\
\text { tipologías de asentamiento, } \\
\text { centros históricos de los núcleos } \\
\text { urbanos u otros conjuntos arqui- } \\
\text { tectónicos (colonias industriales), } \\
\text { estructuras parcelarias y sus } \\
\text { límites (márgenes, muros), } \\
\text { sistema de riego autóctonos, etc.» }\end{array}$ \\
\hline
\end{tabular}

Fuente: elaboración propia a partir de Kellert (1993) y Ribas (2007). 
nos-; el valor estético; los valores simbólicos, mitológicos y relacionados con la identidad ${ }^{1}$ — que vinculamos a los valores simbólicos y moralistas de Kellert, referidos no solo a la reacción emocional que provoca la naturaleza, sino también al sentimiento ético que inspira-; el valor social — que relacionamos con el aspecto naturalista y humanistico-, y, finalmente, el valor histórico — que interpretamos en el sentido de situarlo en la esfera de los valores dominante y negativo que propone Kellert, ya que se trata de dos fuerzas que, aunque contrapuestas, confluyen en el deseo humano de controlarla para evitar sus efectos negativos sobre el conjunto de la sociedad ${ }^{2}$. De los valores propuestos por esta relación de autores se desprende una conclusión clara: la relación entre sociedad y naturaleza se verifica a diferentes escalas y, sin duda, se materializa en la multiplicidad de vínculos existentes entre una ciudad y un río.

\section{El enfoque histórico-urbanístico en el estudio de ríos y ciudades}

En la historia de la sociedad humana, las masas de agua superficiales en sus distintas variantes - principalmente fluviales, lacustres y marinas - han sido básicas para el transporte y el intercambio de mercancías entre diferentes regiones, pueblos y culturas. De hecho, el agua ha tenido un papel fundamental en el mismo origen de la urbe ${ }^{3}$. Numerosas capitales nacionales y regionales de Europa han crecido cerca de un río o se han ensanchado en sus márgenes: París y el río Sena, Roma y el Tíber, Londres y el Támesis, Viena y el Danubio, Lyon y el Ródano y el Saona, Varsovia y el Vístula, Zaragoza y el Ebro o Sevilla y el Guadalquivir son ejemplos paradigmáticos. En un sentido equiparable,

1. Sobre el simbolismo del agua en el paisaje, es interesante hacer referencia a las reflexiones del investigador Graham Fairclough sobre este asunto, pues no solamente considera que "el agua tiene una importante carga simbólica», sino que incluso "el agua se convierte en un símbolo del propio paisaje si adoptamos una idea (y una realidad) de paisaje que va más allá de las definiciones tradicionales de un paisaje esencialmente visual y lo convierten (¡de nuevo?) en un elemento de unión entre las personas, los lugares y el medio» (Fairclough, 2016: 211-212).

2. Consideramos muy pertinentes, en este sentido, las siguientes palabras en referencia a este asunto: «La mayoría de la gente percibe el río como un inconveniente a la vez que se construye una imagen idílica e irreal del mismo. Incluso se encuentran aún personas que conservan frente al río aquella visión utilitaria, respetuosa y temerosa ancestral» (Ascorbe et al., 1999: 94).

3. Las primeras grandes civilizaciones neolíticas decidieron asentarse en valles fluviales para desarrollar su cultura. Son lo que, desde la visión histórica, se conoce como hydraulic civilizations (Wittfogel, 1957), formadas alrededor de seis grandes ríos: la cultura mesopotámica, a orillas del Tigris y el Éufrates; la egípcia, cerca del Nilo; la índia, en las márgenes del río Indus, y, finalmente, la china, entre los ríos Yangtsé y Huang-He. El desarrollo estratégico de estas primeras civilizaciones las lleva a convertirse, durante mucho tiempo, en protagonistas de grandes imperios, donde la gestión y el control del agua influye en su jerarquización política y religiosa. En esta misma línea se expresa Cosgrove (1990), cuando afirma que estas civilizaciones basan su desarrollo vital en el control ingenieril del agua, describiéndolas de la siguiente manera: «[...] a specific type of social formation founded upon centralized state authority with it own forces and relations of production emerging out of water engineering and control»(Cosgrove, 1990: 2). 
otras ciudades presentan grandes infraestructuras hidráulicas: Ámsterdam y su sistema de canales semicirculares o bien Padua y las vie d'acqua. Cabe anotar, también, diferentes casos que se caracterizan por una relación especialmente intensa, original o singular con el mar: así, Venecia o Barcelona y el Mediterráneo; Copenhague y el mar Báltico, o Helsinki y el golfo de Finlandia.

En este apartado abordamos el análisis de tres conceptos básicos en la literatura científica especializada en los vínculos históricos y urbanos entre ríos y ciudades: la relación entre ciudad y río, la interfaz entre ciudad y rio y el espacio urbano-fluvial. Se trata de conceptos utilizados para describir la evolución histórica, física y espacial de las ciudades fluviales. No obstante, como podremos ver en los epígrafes siguientes, se habla de uno u otro en función del diferente énfasis que se haga en el vector «espacio» y en el vector "tiempo». Así, la relación entre ciudad y río es un concepto que se utiliza más bien en relación con el plano temporal, mientras que los de interfaz entre ciudad y rio y de espacio urbano-fluvial se centran preferentemente en el plano espacial y físico.

\subsection{Una convivencia ineludible en el espacio y en el tiempo: la interfaz $y$ la relación entre ciudad y rio}

En la figura 2 tratamos de sintetizar, a partir de los trabajos previos de varios autores, el amplio abanico de conexiones que conciernen a la interacción entre una ciudad y un río en su conjunto, interacción entendida como el resultado de la multiplicidad de vínculos establecidos a través del espacio y del tiempo. El esquema que presentamos dibuja un escenario que, por encima de su complejidad aparente, trata de aportar claridad al discernimiento de dos conceptos que, aunque usados a menudo como sinónimos, cabe también considerar, argumentadamente, de forma diferenciada: la interfaz entre ciudad y rio y la relación entre ciudad y río.

Según el Diccionario de la Real Academia Española (DRAE), una interfaz es la «conexión o frontera común entre dos aparatos o sistemas independientes». Por lo tanto, se puede deducir que la llamada interfaz entre ciudad y río describe el espacio físico de contacto entre el medio urbano y el fluvial; un espacio que se materializa en una frontera - a veces clara y evidente, a veces tenue y difusa, según la potencia de la urbanización antrópica- que separa diferentes usos del suelo según el caso de estudio en particular. A su vez, estos usos se encontrarán fuertemente influidos por las características del medio físico.

En relación con la cuestión que nos ocupa, Ureña (1999) subraya que el medio fluvial y el medio urbano presentan características diametralmente opuestas. Por un lado, los ríos son áreas de cambio constante, tienen una diversidad muy elevada, son el resultado de la integración entre el ámbito fluvial y el terrestre, se pueden considerar un verdadero sistema ${ }^{4}$, su comportamiento

4. Es conveniente matizar estas palabras. Si bien Ureña (1999) señala que solamente el medio fluvial puede considerarse como un (eco)sistema, la visión que encarnan autores como 
Figura 2. Esquema ilustrativo de la relación entre ciudad y río, entendida como resultado de los vínculos espaciales y temporales entre lo urbano y lo fluvial

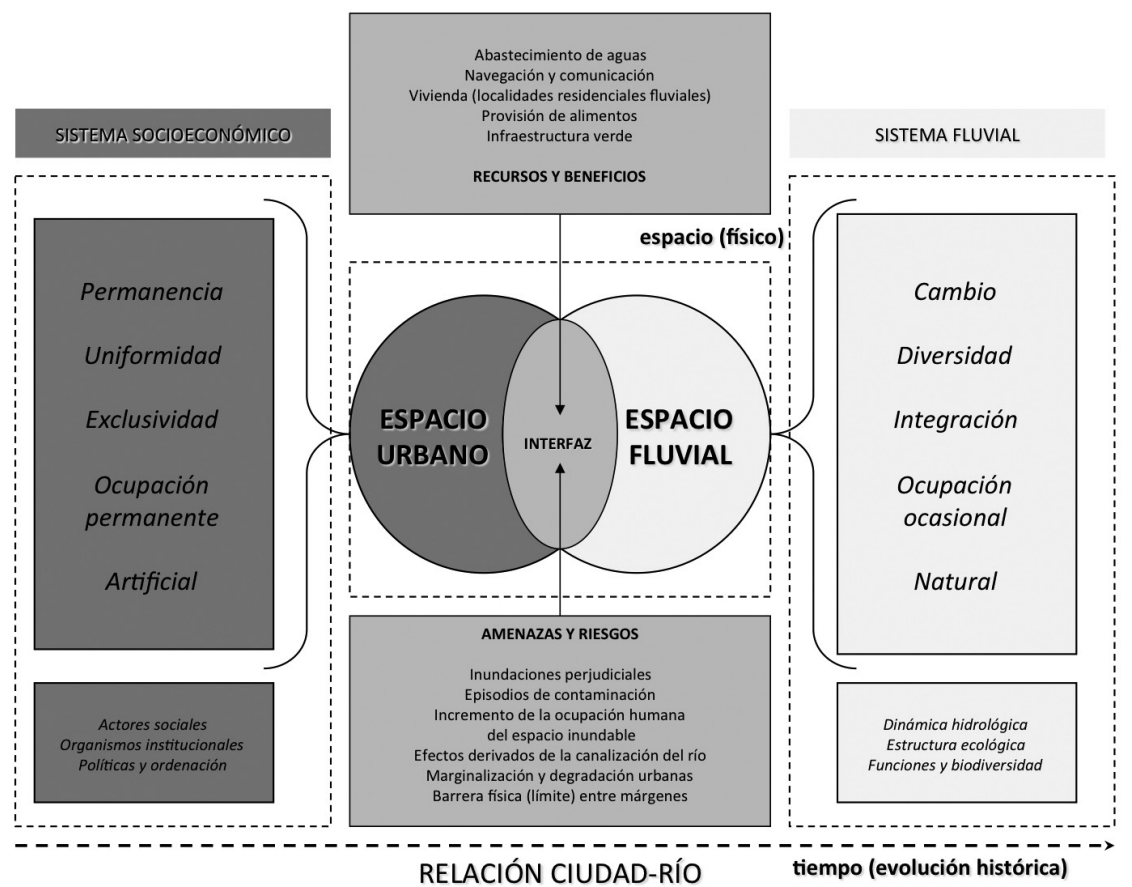

Fuente: elaboración propia a partir de Penning-Rowsell (1997), Ureña (1999, 2002), Béthemont (1999), Gérardot (2007) y Delahaye (2009).

hidrológico responde a una ocupación ocasional y efímera del territorio y, por encima de todo — señala el autor-, los ríos son producto de la naturaleza. Por otra parte, según el propio Ureña, las áreas urbanas se caracterizan por una permanencia constante y por una uniformidad geométrica, sus usos son diferenciados y exclusivos, se encuentran afectadas por una fragmentación administrativa que no coincide con la división ecosistémica, constituyen unos espacios de ocupación permanente y, finalmente, son un producto humano. De esta manera se hace evidente la ambivalencia existente entre un medio y otro, que se concreta en un campo físico sometido a fuerzas diversas y contradictorias.

Si la interfaz entre ciudad y río describe los vínculos físicos, espaciales y materiales entre el medio urbano y el fluvial, el concepto de relación entre

Béthemont (1999), Gérardot (2007) o Delahaye (2009) diferencia entre sistema fluvial (en lengua francesa, hydrosistème) y sistema socioeconómico. Aun así, no parece que se trate de visiones completamente opuestas. Intuimos que la visión de Ureña responde a una interpretación estrictamente material del espacio urbano, mientras que la de los autores franceses responde a una visión social que incluye los distintos actores implicados en la gestión de los espacios urbanos y fluviales y la práctica de sus políticas. 
ciudad y río pone el acento, necesariamente, en la evolución histórica, es decir, en la consideración sobre cómo se han visto transformados - mutados, interrumpidos, reformulados- estos vínculos en cada época. Pellicer (2001: 283) constata que la correlación entre medio fluvial y urbano se resuelve de forma muy diversa en el espacio y en el tiempo «en función de acontecimientos históricos (avenidas), de las soluciones técnicas, de la disponibilidad económica, de la consideración social del espacio fluvial o de la sensibilidad por el paisaje». Otros autores, como Penning-Rowsell (1997), consideran los vínculos entre las ciudades y los ríos como una mezcla de recursos y ventajas, por una parte, y de amenazas y riesgos, por otra. Se trata, en cierto modo, de una convivencia que se va convirtiendo en un reto continuado a lo largo de la historia de los seres humanos. En la literatura científica francesa, dos autores destacados como Labasse (1989) y Pelletier (1990) identifican también la llamada couple ville-fleuve como una relación dialéctica entre «inconvenientes», por un lado, $\mathrm{y}$ «méritos», por otro:

Ce rôle, ils l'ont joué autant par leurs inconvénients (inondations, aléas topograhiques, phénomènes d'erosion) que par leurs mérites propres: facilité de défense, fonds d'estuaires (Londres, Rouen) possibilité de passage par un gué (Oxford) ou par un pont, confluences remarquables (Saint-Louis, Manaus, Lyon), boucles de méandres (Vérone, Besançon). (Labasse, 1989: 11)

Le thème de la ville saisie dans ses relations avec l'eau est un des plus féconds de la géographie urbaine. L'eau est présente dès l'origine des cités, non seulement en déterminant souvent leer naissance (pont, gué, force motrice, navigation...) mais dans les aspects variés de son utilisation pour l'alimentation, l'hygiène, les loisirs, l'industrie et les transports; mais aussi élément générateur de contraintes, obstacle à franchir, champ d'inondation; et enfin élément riche de potentialités par les facilités de communications intra-urbaines ou extérieures qu'il offre souvent. (Pelletier, 1990: 233)

Es interesante subrayar, en todo caso, las «fases» o "ciclos» históricos que determinados autores identifican en la relación histórica entre ríos y ciudades en sus trabajos. El ya citado Penning-Rowsell (1997) expone que, a lo largo del tiempo, se han registrado diferentes ciclos de acercamiento y de alejamiento, en los cuales, por determinadas circunstancias, la relación entre ciudad y río ha oscilado entre la marginalidad y la centralidad. En la misma línea, autores como Monclús (2002) también argumentan que es importante alejarse de expresiones como «dejar de dar la espalda al río», puesto que a menudo incurren en el tópico. En efecto, según este autor, aunque en ciertos casos los ríos urbanos han constituido espacios marginales y se han visto marginados por la ciudadanía - lo que ha promovido que fueran restaurados y regenerados en las últimas décadas - , también han sido durante mucho tiempo las «puertas comerciales» de las ciudades, con un uso y un aprovechamiento social muy notables. Así pues, la recuperación reciente de ciertos tramos fluviales urbanos supone, en todo caso, un «ciclo» de acercamiento reciente, que forma parte 
del conjunto del espectro histórico en el que se desenvuelve la relación entre ríos y ciudades.

\subsection{Un "concepto paraguas»: el espacio urbano-fluvial}

Un término interesante desde el punto de vista geográfico por su amplitud conceptual es el llamado espacio urbano-fluvial (presente en trabajos como los de Calvo García-Tornel, 1997; Pellicer, 2001; Ribas, 2007 o Mulero, 2016). Tal y como especifica en su tesis doctoral la autora francesa Delahaye (2009), este concepto alude, en un sentido amplio y generalista, al espacio de interacción entre una ciudad y un río en función de un criterio propio de la geografía física: la delimitación correspondiente a la llanura de inundación. No pone el acento, pues, en la morfología urbana o en la tipología fluvial, sino en todo aquel espacio urbanizado susceptible de ser inundado por las aguas del río.

Es particularmente interesante la visión que ofrece esta autora con su aportación al desarrollo conceptual del término - que, en lengua francesa, se conoce como espace fluvio-urbain ${ }^{5}$ - . A partir de la observación del transecto entre el río y el espacio inundable, Delahaye (2009) propone una tipología de espacios urbanos comunes a la mayor parte de ciudades fluviales: ville-basse - concepto que responde a la parte histórica de una ciudad en contacto directo con el río-; quartier fluvial - término que la autora utiliza para referirse a un barrio, adyacente a un río, en el cual se desarrollan actividades económicas o de ocio relacionadas con el agua-, y, finalmente, quartier riverain $d u$ fleuve - concepto que comprende, a efectos prácticos, aquellos barrios que se encuentran menos influidos por el riesgo de inundación-. Se trata, pues, de una teoría general que intenta describir la ocupación urbana del sistema fluvial a partir de una serie de patrones observados. Además, plantea la necesidad de adoptar otro concepto para nombrar y comparar, de forma específica, la exposición longitudinal del espacio urbano a lo largo de un río: fenêtre fluvial - concepto que todavía no cuenta con una traducción homologada y que, por tanto, carece por el momento de difusión en estudios anglosajones o españoles-. En todo caso, se trata de conceptos relativamente nuevos en este campo y que, probablemente, necesitan un mayor desarrollo científico.

\section{Una transformación reciente: waterfronts, riverfronts y fachadas urbanas}

Tal y como señalan varios autores (Bravard, 2002; Gérardot, 2007; Carré y Deutsch, 2015), a partir de los años setenta y ochenta ha tenido lugar una

5. En la literatura académica francesa aparecen otros conceptos y expresiones similares. DupuisTate (1998) se refiere a estos espacios con el término alternativo de espaces-rivières. Micoud (1995), aunque no se ciñe a esta definición de carácter geomorfológico, propone un amplio abanico de conceptos similares: espaces intermédiaires, espaces lisières, espaces semi-naturelles, espaces ambivalentes y espaces d'entre-deux. 
transformación profunda de los espacios fluviales en varias ciudades de Europa. Ríos que, en los años sesenta, representaban un espacio deteriorado y contaminado se han convertido, mediante proyectos de regeneración urbana - rehabilitación ambiental, revalorización de los usos, recalificación del suelo- en nuevos ámbitos de centralidad para los ciudadanos (figura 3). Es lo que se ha calificado, de un modo un tanto metafórico ( $y$, normalmente, en trabajos de tradición francesa) como la reconquête sociale. Se trata, sencillamente, de la «devolución a la ciudadanía» de unos espacios generalmente degradados y que se encontraban hasta entonces afectos a una actividad privada y sin posibilidad, por tanto, de ser disfrutados y valorados por el público. Es un proceso ligado a fenómenos de naturaleza diversa, como la posibilidad de controlar el riesgo del agua en la ciudad o la existencia misma de una planificación urbana más sensible al entorno fluvial. Incluso creemos que podría hablarse, en ocasiones, de una cierta «connivencia mimética» respecto a los procesos de renovación de los espacios portuarios norteamericanos (Gravari-Barbas, 1991).

Se trata, pues, de un fenómeno que manifiesta un cambio notable de modelo de gestión del agua y los espacios fluviales en el entorno urbano. Hecho que, precisamente, los autores ya mencionados Carré y Deutsch (2015) sintetizan mediante la constatación de un evidente "cambio de filosofía" por parte de las administraciones locales y regionales, que encarnan, a lo largo de los últimos siglos, la sucesión de tres visiones a la hora de planificar y gestionar el agua en la ciudad: la filosofía higienista — que empieza a desarrollarse a partir del siglo XIX y se basa en asegurar el acceso al agua a la población para evitar miasmas y enfermedades—; la filosofía hidráulica — que tiene su máximo esplendor en la década de los años cincuenta y sesenta, y enfoca sus esfuerzos en la correcta y eficiente captación y distribución del agua, por encima de la variable ecológica-, y, finalmente, la filosofía ambiental —la más reciente, desarrollada a partir de los años setenta, y que considera como prioritaria la dimensión ambiental del agua en todas sus facetas.

Cuando los geógrafos, los urbanistas y los arquitectos han intentado comprender y explicar la transformación de los espacios urbano-fluviales, han utilizado diferentes conceptos. Uno de los más empleados ha sido el de waterfront. Se trata de un término complejo, de fronteras notablemente difusas y que varios autores han tratado de definir en diferentes ocasiones. Timur (2013) realiza un compendio básico de las diferentes definiciones de este concepto existentes en la literatura científica, de las cuales consideramos que es necesario destacar la aportación de la historiadora Marta Moretti (2010):

The word waterfront identifies the urban area in direct contact with water. In cities on water, this area usually corresponds to the area occupied by port infrastructures and port activities. (Moretti, 2010: 4)

Así pues, el concepto de waterfront se explica a través de una definición acotada, que responde concretamente al espacio de contacto entre la franja urbana y el mar, y sobre la base de la actividad por excelencia que tiene lugar 
Figura 3. La fachada fluvial del río Ródano en Lyon (Francia). En la imagen se observa una zona de descanso y un juego de aguas: es lo que se conoce como Les Terrasses de la Guillotière, una de las zonas urbanas más valoradas del proyecto Berges du Rhône. En 2005 esta zona era un aparcamiento para coches

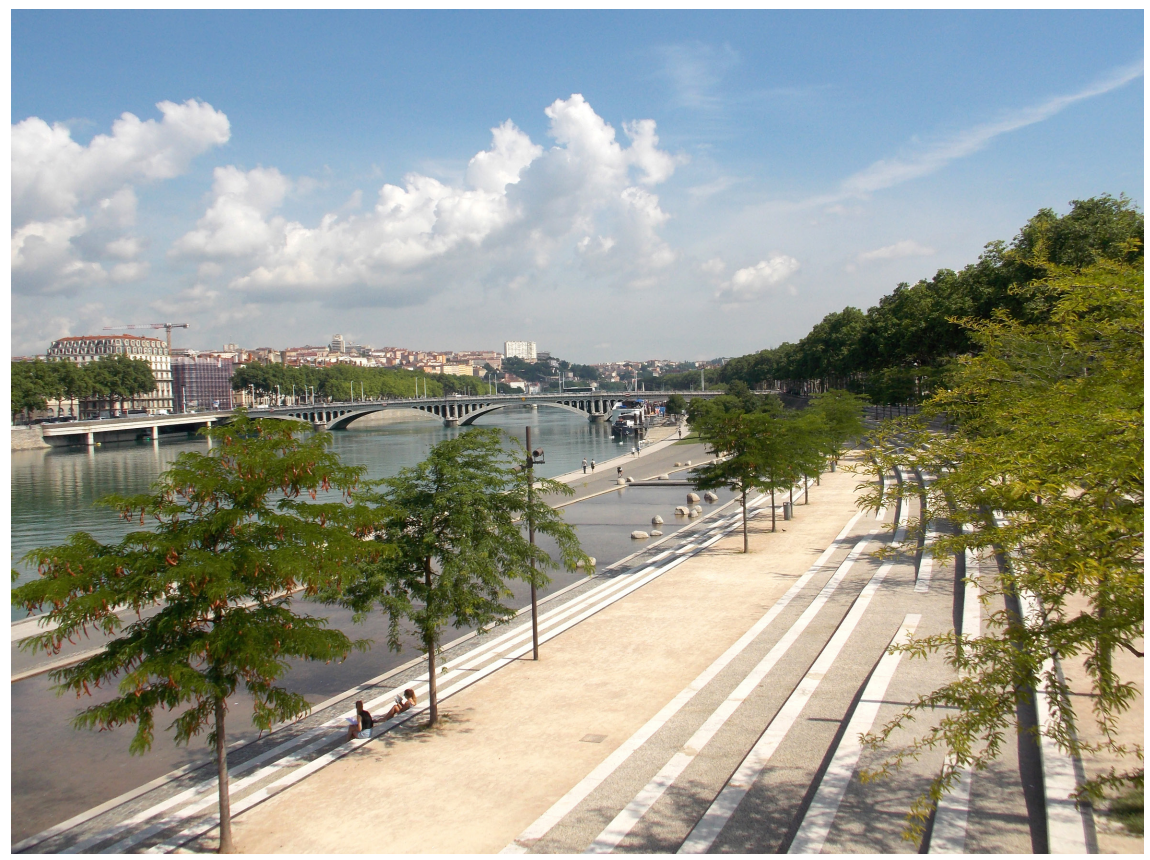

Fuente: archivo propio de Albert Santasusagna (tomada en junio de 2015).

en el mismo: la portuaria ${ }^{6}$. Esta visión, ampliamente difundida a través de las definiciones que recoge Timur, también la sostienen otros autores franceses como el urbanista Claude Chaline (1994), que se refiere a waterfront de la siguiente forma:

L'ensemble de territoires naguère occupés de manière quasi-exclusive par les activités maritimes, industrielles et leurs compléments obligés et notamment les emprises ferroviaires. (Chaline, 1994: 72)

No obstante, existe una visión más abierta del término, que coincide con la que la geógrafa Gravari-Barbas sostiene en sus trabajos. Esta autora francesa señala que no se trata solamente de un concepto para referirse a la franja de contacto entre espacio urbano y marítimo, sino que es necesario abrirse a otros

6. Gravari-Barbas (1991) describe, en su tesis doctoral, la transformación de los waterfronts a lo largo de los años sesenta en ciudades norteamericanas como Baltimore, Boston, Chicago, San Francisco y Seattle. En efecto, el concepto original de waterfront se encuentra íntimamente relacionado con los procesos de revitalización urbana de estos espacios portuarios. 
escenarios donde el agua es protagonista y, por lo tanto, se puede utilizar para describir «les fronts de mer, de fleuve ou de lac» (Gravari-Barbas, 1998: 261). Bajo esta premisa nace el concepto de riverfront, un concepto que se refiere, fundamentalmente, al espacio de contacto entre la zona urbana y el curso fluvial. Este término se conoce como front d'eau urbain o front de fleuve en lengua francesa y como fachada fluvial urbana en lengua castellana, aunque también es utilizado, como sinónimo, frente fluvial.

En la misma línea que Gravari-Barbas se expresa Delahaye (2009), que considera que waterfront puede referirse a la franja urbana de contacto con cualquier masa de agua (principalmente marina, fluvial o lacustre) y no necesariamente vinculada a las actividades industriales y portuarias:

Les «waterfronts» ne relèvent donc pas exclusivement du domaine fluvial mais plutôt du domaine maritime [...] Ce sont en outre des espaces essentiellement portuaires, ce qui n'est pas nécessairement le cas des fronts fluviaux urbains. (Delahaye, 2009: 44)

En consecuencia, nos encontramos ante unas definiciones que difieren entre sí y basculan entre dos elementos básicos: la consideración de la masa de agua, por un lado, y las actividades que se llevan a cabo en el espacio urbano, por el otro. En resumen: la definición más restringida defiende que un waterfront hace referencia al espacio portuario de aquellas ciudades abiertas al mar y susceptible de ser transformado a partir de una operación de regeneración urbana. En cambio, la definición más abierta reconoce varios escenarios: masas de agua, actividades urbanas y usos del suelo distintos — definición en la que nos reconocemos-. A modo de síntesis, en la figura 4 tratamos de incorporar en un mismo esquema los términos científicos relativos a la relación entre agua y espacio urbano desde la perspectiva de los conceptos de paisaje y de fachada urbana, con la intención de reunir y ordenar de un modo unitario la numerosa cantidad existente de términos en relación con esta cuestión.

En cualquier caso, los conceptos de referencia (waterfront, riverfront), sean estudiados desde una perspectiva amplia o bien desde ópticas concretas y acotadas, constituyen vocablos que tienen como objetivo facilitar el análisis y la interpretación de los «espacios de contacto» entre el agua y la ciudad, así como su evolución a lo largo del tiempo. La colonización histórica de las márgenes fluviales, la evolución de los usos de estos espacios y los cambios en las estrategias de desarrollo nos permiten observar que, a escala europea, y tal y como expresábamos en la introducción de este apartado, los espacios urbanos en contacto con el agua $-\mathrm{y}$, concretamente, con un curso fluvial - tienden a ajustarse, en su mayoría, a unas tendencias y a unas características formales determinadas. La primera de ellas es que el agua, en sus múltiples facetas, tiene un papel fundamental en sus funciones, usos y actividades — desde el aprovechamiento hidroeléctrico hasta una función meramente estética-. Otra tendencia observada es que estos espacios acostumbran a presentar una coherencia lineal (entendida en un sentido amplio) en su función urbana. 
Figura 4. Representación gráfica de los principales conceptos derivados de la relación entre agua y espacio urbano. Se presentan en lengua inglesa, francesa y castellana. Si bien no se incluye en la figura, constatamos que también existe, en la literatura científica anglosajona, el vocablo canalscape para referirse concretamente a los paisajes del agua correspondientes a los canales artificiales (Curulli, 2012)
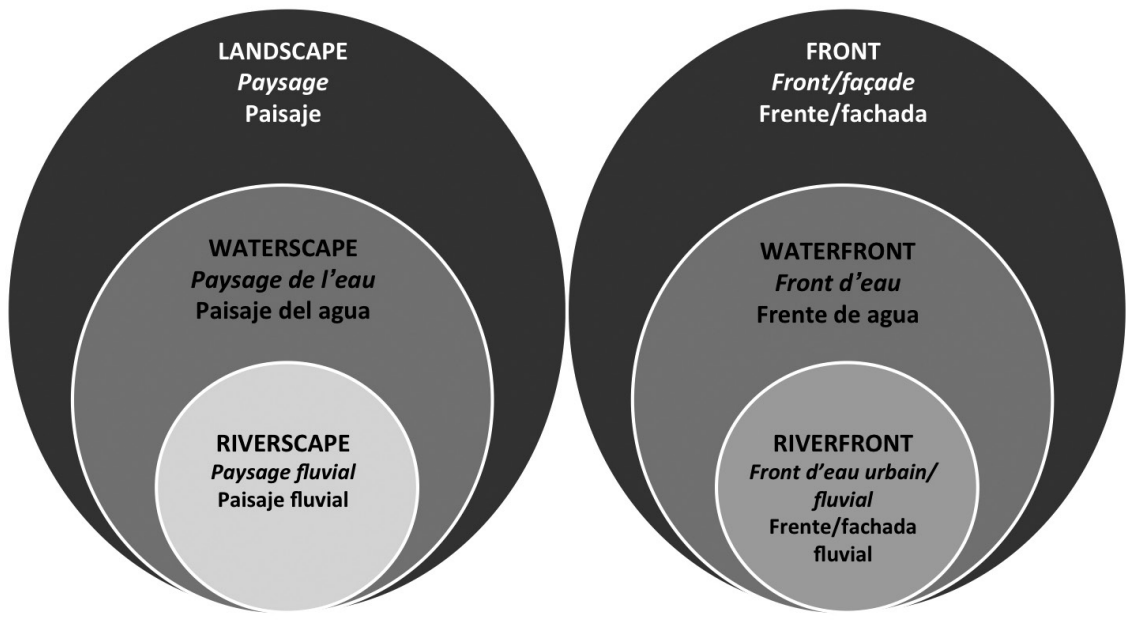

Fuente: elaboración propia.

Son, de hecho, unas franjas urbanas que pueden considerarse morfológicamente diferenciadas del resto de espacios que integran y conforman la ciudad. $Y$, finalmente, otra característica habitual es que muchos de estos espacios han sufrido un cambio o una pérdida de usos que, a lo largo del tiempo, ha derivado en una recalificación a través de proyectos de regeneración urbana - proyectos que, desafortunadamente, no siempre han contemplado debidamente la variable ecológica y no han aplicado medidas de restauración ambiental (Ollero, 2011).

Queremos dar fin a este apartado con unos párrafos escritos por el geógrafo Lorenzo López Trigal. Su visión, como podemos observar, encarna la definición amplia de waterfront - o de fachada urbana - a que nos hemos, fundamentalmente, referido. A ello se añade una cierta dosis de crítica que, aunque no concierne de un modo directo a este artículo, consideramos que, desde nuestro punto de vista, es absolutamente necesaria:

Estamos en una época en la que se habla cada vez más entre nosotros de las fachadas atlántica o mediterránea como espacios de grandes regiones a nivel de la cooperación transfronteriza o interurbana, a la vez que siempre se ha hablado de politica de fachada, equivalente a menudo a actuaciones del tipo de "haz donde se vea y no donde haga falta» al referirse a la ciudad, que se traduce en lo relativo a la construcción de la fachada urbana. Concepto éste que a menudo se acompaña de una fachada «más vista» que presenta la mejor imagen, la más bellamente vestida de la ciudad, pero frecuentemente tras la 
fachada hay un espacio menos visto, la parte trasera donde no se ha llevado a cabo el embellecimiento. Por otra parte, es común que esa política de fachada se concentre, con mayor o menor acierto, en los bordes litorales o fluviales de las ciudades, siendo excepcional la ciudad con fachada litoral a la vez que fluvial. (López Trigal, 1996: 441)

\section{Recapitulación final}

Hemos podido constatar, a lo largo del artículo, la multiplicidad de enfoques, observaciones, precisiones y definiciones existentes sobre la relación entre agua y espacio urbano. Se trata, a rasgos generales, de conceptos nacidos de diversas tradiciones geográficas - hemos incluido, en el análisis, las perspectivas anglosajona, francesa y española-, con un encuadre particular pero con un objetivo común: el estudio de los vínculos establecidos, a diferentes niveles y escalas, entre la naturaleza y la sociedad $-\mathrm{y}$, a pequeña escala, entre una ciudad y un río. En todo caso, llegamos a la conclusión de que la mayoría de conceptos analizados han sido tratados en la literatura científica desde una perspectiva transversal, con el único fin de considerar todas las posibles dimensiones del hecho urbano-fluvial. Y, por otra parte, estos conceptos han sido desarrollados por diferentes campos disciplinarios (geografía, urbanismo, arquitectura) y con acento, indistintamente, en aspectos históricos, políticos, sociales, ambientales y urbanos. En conclusión, nuestra investigación demuestra el gran interés que ha despertado este objeto de estudio en todas estas disciplinas, pero sobre todo en la geografía de las últimas décadas. Convenimos que la «mirada» que brinda la geografía — amplia, concurrente y transdisciplinaria - ha representado una gran ventaja en el desarrollo científico de este objeto de estudio. Un hecho que, en la práctica, se ha reflejado en el elevado número de publicaciones que le conciernen, aparecidas en los últimos decenios y que, más allá de su eventual divergencia en términos de tradición académica, apuntan generalmente a un mismo modo de plantear los interrogantes de fondo.

\section{Referencias bibliográficas}

Ahlers, Rhodante; Cleaver, Frances; RusCa, Maria y SchWartZ, Klaas (2014). «Informal Space in the Urban Waterscape: Disaggregation and Co-Production of Water Services». Water Alternatives, 7 (1), 1-14.

Anton, Michael; Garrett, Bradley L.; Hess, Alison; Miles, Ellie y Moreau, Terri (2013). «London’s Olympic waterscape: Capturing transition». International Journal of Heritage Studies, 19 (2), 125-138.

<http://doi.org/10.1080/13527258.2011.643911>

ARDILLIER-CARRAS, Françoise (1998): «Les paysages de rivière: une valeur refuge». Revue de Géographie de Lyon, 73 (4), 309-319. <http://dx.doi.org/10.3406/geoca.1998.4846>

Ascorbe, Agustín; CANTERAS, Juan Carlos; Puente, Leonor de la; GarCía Codrón, Juan Carlos; GaRMENDIA, Carolina; Liaño, Andrés; RIVAS, Victoria; SAINZ BORDA, Ángel y UREÑA, José María (1999). «Ordenación de las áreas fluviales en el Norte 
de España: El río Saja». En: UREÑA, José María (ed.). River design and environmental protection in Europe. Ordenación y protección ambiental de rios en Europa. Aménagement et protection environnementale des rivières en Europe. Santader: Universidad de Cantabria, 61-194.

Beltrán, María José y VelázQuez, Esther (2015). «La ecología política del agua virtual y huella hídrica: Reflexiones sobre la necesidad de un análisis crítico de los indicadores de flujos virtuales del agua en la economía». Revista de Economía Critica, 20, 44-56.

Béthemont, Jacques (1999). Les grands fleuves. París: Armand Colin.

Béthemont, Jacques y Bravard, Jean-Paul (2016). Pour saluer le Rhône. Lyon: Éditions Libel.

BÉTHemont, Jacques y PIÉGAY, Hervé (1998). «Les paysages des cours d'eau: Structure, perception, gestion». Revue de Géographie de Lyon, 73 (4), 331-335.

Béthemont, Jacques; Rivière-HonegGer, Anne; Le LaY, Yves-François (2007). «Les paysages des eaux douces». Géoconfluences: ressources de géographie pour les enseignants. Dosier electrónico Le paysage dans tous ses états <http://geoconfluences.enslyon.fr/doc/transv/paysage/PaysageScient2.htm>.

Bravard, Jean-Paul (1987). Le Rhône, du Léman à Lyon. Lyon: La Manufacture.

- (2002). «La gestión de los ríos en el medio urbano: tendencias francesas». En: Cal, Pablo de la; Pellicer, Francisco (coords.). Ríos y ciudades: Aportaciones para la recuperación de los ríos y riberas de Zaragoza. Zaragoza: Institución Fernando el Católico, 211-228.

Bravard, Jean Paul; Laurent, Anne-Marie; Davallon, Jean y BÉthemont, Jacques (1995). Les paysages de l'eau aux portes de la ville. Lyon: PPSH Rhône-Alpes, Centre Jacques Cartier.

BUDDS, Jessica (2008). «Whose scarcity?: The hydrosocial cycle and the changing waterscape of La Ligua river basin, Chile». En: GOODMAN, Michael K.; BoyKOFF, Maxwell T.; Evered, Kyle T. (eds.). Contentious Geographies: Environmental Knowledge, Meaning, Scale. Londres: Routledge, 59-68.

BUSQUETS, Joan (2004). "Los waterfronts de segunda generación». Cartas Urbanas, $10,172-201$.

Calvo García-Tornel, Francisco (1997). "Las transformaciones de los espacios urbanos fluviales en zonas áridas: Lecciones de la cuenca del Segura». Documents d'Anàlisi Geogràfica, 31, 85-102.

- (2001). Sociedades y territorios en riesgo. Barcelona: Ediciones del Serbal.

CARRÉ, C. y DEUTSCH, J.C. (2015). L'eau dans la ville: Une amie qui nous fait la guerre. París: Éditions de l'Aube.

Chaline, Claude (1994). Ces ports qui créerent des villes. París: L'Harmattan.

Corbella, Domènec (2016). L'art de l'aigua: Aqua et ars in unum miscentur. Barcelona: Edicions de la Universitat de Barcelona.

Cosgrove, Denis (1990). «An elemental division: Water control and engineered landscape». En: Cosgrove, Denis y PETTS, Geoff (eds.). Water engineering and landscape. Londres: Belhaven Press, 1-11.

- (1993). The Palladian landscape. Londres: Leicester University Press.

Cuello, Agustín (2010). «Los tramos fluviales urbanos como ámbitos de aprendizaje: Una valoración de su potencial educativo y los obstáculos que plantea su utilización». En: JUNYENT, Mercè y CANO, Luís (coords.). Investigar para avanzar en educación ambiental. Madrid: Organismo Autónomo Parques Nacionales. Ministerio de Medio Ambiente y Medio Rural y Marino, 65-85. 
Cuello, Agustín y Cuello, Maribel (2016). «Crecimiento urbano y espacio fluvial: Una mirada educativa». En I Jornadas de Periferias Urbanas. Sevilla: Universidad de Sevilla. Escuela Técnica Superior de Arquitectura, 217-232.

CuRUlli, Irene (2012). Industrial canal waterfronts in the Netherlands: Transforming the Canal Zones of B5. Florencia: Alinea International Editrice.

DELAHAYE, Emmanuelle (2009). Les espaces fluvio-urbains rhodaniens à l'aval de Lyon, Vienne, Valence, Avignon, Tarascon, Beaucaire et Arles: Des territoires à la dérive? Lyon: Université Lyon 2. Tesis doctoral.

Descola, Philippe (2005). Par-delà nature et culture. París: Éditions Gallimard.

Dupuis-TATE, Marie-France (1998). «Le paysage fluvial des paysagistes d'aménagement». Revue de Géographie de Lyon, 73 (4), 285-292. <http://doi.org/10.3406/geoca.1998.4843>

Espluga, Josep; BALlester, Alba; HernándeZ-Mora, Núria y Subirats, Joan (2011). "Participación pública e inercia institucional en la gestión del agua en España». Reis: Revista Española de Investigaciones Sociológicas, 134, 3-26. <http://doi.org/10.5477/cis/reis.134.3>

FAIRCLOUGH, Graham (2016). «En el lugar y el momento adecuados: El agua en los paisajes humanos». En: NoguÉ, Joan; PuigBert, Laura y BretCHA, Gemma (eds.). Paisatge, patrimoni i aigua: La memòria del territorio. Olot: Observatori del Paisatge de Catalunya, 210-212.

Frolova, Marina (2007). «El estudio de los paisajes del agua en una cuenca vertiente: Propuesta metodológica». Revista de Estudios Regionales, 83, 21-47.

GÉRARDOT, Claire (2007). Fleuves et action urbaine: de l'objet à l'argument géographique: Le Rhône et la Saône à Lyon, retour sur près de trente ans de reconquête des fronts urbains à Lyon. Lyon: Université Lyon 2. Tesis doctoral.

Gierlinger, Sylvia; Haidvogl, Gertrud; Gingrich, Simone y Fridolin, Krausmann (2013). «Feeding and cleaning the city: The role of the urban waterscape in provision and disposal in Vienna during the industrial transformation». Water History, 5 (2), 219-239. <http://doi.org/10.1007/S12685-013-0075-1>

GraVARI-BARBAS, Maria (1991). La mer retrouvée: Baltimore et autres reconquêtes de fronts d'eau urbains. París: Université Paris-Sorbonne. Tesis doctoral.

- (1998). «La «Festival Market Place» ou le tourisme sur le front d'eau: Un modèle urbain américain à exporter?». Norois, 178 (1), 261-278. $<$ http://doi.org/10.3406/noroi.1998.6868>

Huning, Sandra y Frank, Susanne (2011). «Urban Waterscapes as Products, Media and Symbols of Change - The Re-invention of the Ruhr». EFLA Regional Congress of Landscape Architecture Proceedings, 1-11.

KarPouzoglou, Timothy y VIJ, Sumit (2017). «Waterscape: a perspective for understanding the contested geography of water». Wiley Interdisciplinary Reviews: Water, $4(3), 1-5$. <http://doi.org/10.1002/wat2.1210>

KELLERT, Stephen R. (1993). «The Biological Basis for Human Values of Nature». En: Kellert, Stephen R. y Wilson, Edward O. (eds.). The biophilia hypotesis. Washington: Island Press, 42-72.

Kellert, Stephen R. y Wilson, Edward O. (1993). The biophilia hypotesis. Washington: Island Press.

KInDER, Kimberly (2015). The Politics of Urban Water: Changing Waterscapes in Amsterdam. Atenas: University of Georgia Press. 
Kooy, Michelle (2014). «Developing Informality: The Production of Jakarta's Urban Waterscape». Water Alternatives, 7 (1), 35-53.

LABASSE, Jean (1989). "Réflexions d'un géographe sur le couple ville-fleuve». En VVAA. La ville et le fleuve: Colloque du $112^{e}$ Congrès National des Sociétés Savantes. Lyon: Éditions du Comité des travaux historiques et scientifiques, 9-22.

LATOUR, Bruno (1991). Nunca fuimos modernos: Ensayo de antropología simétrica. Buenos Aires: Siglo XXI Editores Argentina, 2007.

LOFTUS, Alex (2007). "Working the Socio-Natural Relations of the Urban Waterscape in South Africa». International Journal of Urban and Regional Research, 31 (1), 41-59. <https://doi.org/10.1111/j.1468-2427.2007.00708.x>

LÓPEZ-RIVERA, Diana Marcela (2013). Flows of Water, Flows of Capital: Neoliberalization and Inequality in Medellin's Urban Waterscape. desiguALdades.net - International Research Network on Interdependent Inequalities in Latin America. Working Paper Series, 38.

LÓPEZ TRIgAL, Lorenzo (1996). «Tipologías de fachadas urbanas fluviales en las ciudades castellano-leonesas». En: Ramos Hidalgo, Antonio; Ponce Herrero, Gabino J. y DÁvila Linares, Juan Manuel (coords.). II Jornadas de Geografía Urbana: Recuperación de centros históricos, utopia, negocio o necesidad social. La Geografía de la Percepción como instrumento de planeamiento urbano y ordenación. Las fachadas urbanas, maritimas y fluviales. Alicante: Universidad de Alicante, 441-448.

MARTí-EsCAYOL, Maria Antònia (2005). La construcció del concepte de natura a l'edat moderna: Natura $i$ identitat en el pensament català dels segles XVI $i$ XVII. Bellaterra: Servei de Publicacions de la Universitat Autònoma de Barcelona.

Martín-Vide, Juan Pedro (1999). "Ciudad y río en las artes». OP. Revista del Colegio de Ingenieros de Caminos, Canales y Puertos, 46, 88-95.

Martínez de Pisón, Eduardo (2009). Miradas sobre el paisaje. Madrid: Biblioteca Nueva. Colección Paisaje y Teoría.

Mata Olmo, Rafael y Fernández MuÑoz, Santiago (2010). «Paisajes y patrimonios culturales del agua: La salvaguarda del valor patrimonial de los regadíos tradicionales». Scripta Nova: Revista Electrónica de Geografia y Ciencias Sociales, 14. <http://dx.doi.org/10.1344/sn2010.14.1642>

Mata Olmo, Rafael; Rodríguez, Isabel; Cabrerizo, Casilda y Fernández Muñoz, Santiago (2010). «Gestión del paisaje y gobierno del territorio: Una mirada crítica desde la región urbana de Madrid». Cuadernos de Geografía, 88, 117-140.

Micoud, André (1995). «Point de vue à propos des formes d'intégration sociale et de mise en valeur dans les milieux naturels fluviaux aux portes de la ville». En: BRAVARD, Jean Paul; LaURENT, Anne-Marie; DAVAllon, Jean y BÉTHEMONT, Jacques (eds.). Les paysages de l'eau aux portes de la ville. Lyon: PPSH Rhône-Alpes. Centre Jacques Cartier, 319-327.

MonClús, Francisco Javier (2002). «Ríos, ciudades, parques fluviales, corredores verdes». En: CAL, Pablo de la y Pellicer, Francisco (coords.). Ríos y ciudades: Aportaciones para la recuperación de los rios y riberas de Zaragoza. Zaragoza: Institución Fernando el Católico, 11-31.

MoretTI, Marta (2010). "Valorisation of waterfronts and waterways for sustainable development». International Scientific Conference about Poltva River renewing. Lviv, Ucrania, 19-20 noviembre, 1-58.

Mulero, Antonio (2016). "Córdoba y el Guadalquivir: Hacia la recuperación del espacio fluvial en el entorno monumental de la ciudad». En: OlCiNA, Jorge y Rico, 
Antonio M. (coords.). Libro jubilar en homenaje al profesor Antonio Gil Olcina. Alicante: Publicaciones de la Universidad de Alicante, 327-341.

MuÑoz, María Dolores; PÉREZ, Leonel; SANHUEZA, Rodrigo; URRUTIA, Roberto y RoviRA, Adriano (2006). «Los paisajes del agua en la cuenca del río Baker: Bases conceptuales para su valoración integral». Revista de Geografia Norte Grande, 36, 31-48. <http://dx.doi.org/10.4067/S0718-34022006000200002>

NAREDO, Jose Manuel (2009). El agua virtual y la huella hidrológica en la comunidad de Madrid. Madrid: Canal de Isabel II. Informe de I+D+i.

NovoA, Manuel (1999). "Diluvios, mitos y abundancias». OP: Revista del Colegio de Ingenieros de Caminos, Canales y Puertos, 47, 100-107.

OlCINA, Jorge (2007). Riesgo de inundaciones y ordenación del territorio en España. Murcia: Instituto Euromediterráneo del Agua.

Ollero, Alfredo (2011). «Sobre el objeto y la viabilidad de la restauración ambiental». Geographicalia, 59-60, 267-269.

Pelletier, Jean (1990). "Sur les relations de la ville et des cours d'eau». Revue de Géographie de Lyon, 65 (4), 233-239. <http://doi.org/10.3406/geoca.1990.5741>

Pellicer, Francisco (2001). "Ordenación paisajística de espacios fluviales en ciudades mediterráneas». En: Zoido, Florencio y Venegas, Carmen (coords.). Paisaje y ordenación del territorio. Sevilla: Consejería de Obras Públicas y Transportes. Fundación Duques de Soria, 283-295.

Pellicer, Francisco y Ollero, Alfredo (2004). "Agua y ciudad». Boletín de la Asociación de Geógrafos Españoles, 37, 3-13.

Pellicer, Francisco; Ollero, Alfredo; Ramírez, Santos; Ramiro, Enric y Souto, Xosé Manuel (1994). Paisajes y problemas fluviales. Valencia: Nau Llibres.

Penning-Rowsell, Edmund C. (1997). «Rius i ciutats: Amenaces i potencialitats». Documents d'Anàlisi Geogràfica, 31, 23-34.

Proctor, James (1998). "The social construction of nature: Relativist accusations, pragmatism and critical realist responses». Annals of the Association of American Geographers, 88 (3), 352-376. <http://dx.doi.org/10.1111/0004-5608.00105>

REYT, Philippe (1998a). Formes et paysages de l'eau dans le bassin de la Loire. Villeneuve d'Asq: Presses Universitaires du Septentrion.

- (1998b). «Principes méthodologiques pour l'analyse des paysages de cours d'eau». Revue de Géographie de Lyon, 73 (4), 293-298. <http://dx.doi.org/10.3406/geoca.1998.4844>

RiBAS, Anna (2007). «Los paisajes del agua como paisajes culturales: Conceptos, métodos y una experiencia práctica para su interpretación y valorización». Apogeo: Revista da Associaçao de Professores de Geografia, 32, 39-48.

RIVIÈRE-HONEGGER, Anne (2008). Regards sur les paysages de l'eau: Evolution des usages de l'eau, dynamiques du territoire et mutations paysagères en Méditerranée occidentale. Lyon: École Normale Supérieure de Lyon.

Rodríguez, M.I.; Cuevas, M.M.; Martínez, G. y Moreno, B. (2014). «Planning Criteria for Water Sensitive Urban Design». WIT Transactions on Ecology and the Environment, 191 (2), 1579-1591.

SAurí, David; RiBas, Anna; LARA, Alejandro y PAVÓn, David (2010). «La percepción del riesgo de inundación: Experiencias de aprendizaje en la Costa Brava». Papeles de Geografía, 51-52, 269-278.

<http://dx.doi.org/10.6018/geografia/2016/234741> 
SWYNGEDOUW, Erik (1996). "The city as a hybrid: On nature, society and cyborg urbanization». Capitalism Nature Socialism, 7, 65-80. <http://dx.doi.org/10.1080/10455759609358679>

- (1999). "Modernity and Hybridity: Nature, Regeneracionismo and the Production of the Spanish Waterscape». Annals of the Association of American Geographers, 89 (3), 443-465. <http://doi.org/10.1111/0004-5608.00157>

- (2015). Liquid Power. Cambridge: MIT Press.

Timur, Umut Pekin (2013). «Urban Waterfront Regenerations». En: ÖzYavuZ, Murat (ed.). Advances in Landscape Architecture. Rijeka: InTech, 169-206. <http://dx.doi.org/10.5772/55759>

UREÑA, José María (1999). «Ordenación de las áreas fluviales en las ciudades: Un enfoque metodológico». OP: Revista del Colegio de Ingenieros de Caminos, Canales y Puertos, 46, 4-15.

- (2002). «La ordenación de los espacios fluviales en las ciudades». En: CAL, Pablo de la y PELLICER, Francisco (coords.). Ríos y ciudades: Aportaciones para la recuperación de los ríos y riberas de Zaragoza. Zaragoza: Institución Fernando el Católico, 45-63.

VALlERANI, Francesco (2018). «Flowing consciousness and the becoming of waterscapes». En Vallerani, Francesco y Visentin, Francesco (eds.). Waterways and the Cultural Landscape. Nueva York: Routledge.

WiLson, Edward O. (1984). Biophilia: The human bond with other species. Boston: Harvard University Press.

WiTTFOGEL, Karl August (1957). Oriental despotism: A comparative study of total power. Nueva York: Random House.

Zeitoun, Mark; Eid-Sabbagh, Karim; Talhami, Michael y Dajani, Muna (2013). "Hydro-Hegemony in the Upper Jordan Waterscape: Control and Use of the Flows». Water Alternatives, 6 (1), 86-106.

ZOIDO, Florencio (2008). «Aportaciones para la consideración científica de los paisajes del agua». En: SOBRINO, Julián y CERVERA, Lara (eds.). 2. ${ }^{\circ}$ Coloquio Internacional. Irrigación, energía y abastecimiento del agua: La cultura del agua en el arco mediterráneo. Sevilla: Ayuntamiento de Alcalá de Guadaíra, 31-36.

Zug, Sebastian (2014). The Gift of Water: Bourdieusian capital exchange and moral entitlements in a neighbourhood of Khartoum. Friburgo: Forum Politische Geographie. 